\title{
DESIGN AND ANALYSIS OF PROCESS PARAMETERS ON MULTISTAGE WIRE DRAWING PROCESS- A REVIEW
}

\author{
SHWETA VERMA ${ }^{1} \&$ P. SUDHAKAR RAO ${ }^{2}$ \\ ${ }^{I}$ M.Tech Scholar, Department of Mechanical Engineering, National Institute \\ of Technical Teachers Training and Research, Chandigarh, India \\ ${ }^{2}$ Assistant Professor, Department of Mechanical Engineering, National Institute \\ of Technical Teachers Training and Research, Chandigarh, India
}

\begin{abstract}
This paper presents the brief review on process parameters of wire drawing for aluminium 1080A. The aim is to analyse and numerically study the process parameters using finite element model and also to investigate the effect of forces on drawing of wire. Various research has been done considering different process parameters such as die angle, speed, force, stress, reduction ratio etc. This reasearch paper evaluates the damage during drawing process, speed and temperature effect on drawing stress. An approach is proposed to evaluate the drawing stress by modifying avitzur model assumption.
\end{abstract}

KEYWORDS: Wire Drawing, Finite Element Model, Speed, Die Angle, Reduction Ratio, Temperature \& Stress

Received: Aug 08, 2018; Accepted: Aug 28, 2018; Published: Jan 18, 2019; Paper Id.: IJMPERDFEB201939

\section{INTRODUCTION}

Wire drawing process is one of the most used metal forming processes within the industrial field. In the multistage wire drawing process, the cross- section is reduced by forcing the bar or rod through a whole series of dies [1]. The drawing capability process depends on three main parameters such as wire material properties, die geometries such as die length and die angle, drawing speed and friction at the interface between the die and the wire. Materials traditionally used in this kind of manufacturing process are aluminium, copper alloy, and steel [2]. Aluminium alloy is widely used in fin stock, heat exchanger, dials, name plate, spun hollowware, decorative parts, giftware, cooking utensils, rivets, and reflectors, and sheet metal work [3].

\section{LITERATURE REVIEW}

Aluminium 1080A is used in many applications due to good thermal, mechanical and electrical conductivity parameters. It has light weight compared to steel and cooper, high efficiency and lower cost. The chemical composition of wire materials are shown in table (1).

Table 1: Composition of The Al 1080A

\begin{tabular}{|l|l|}
\hline Element & Content (\%) \\
\hline $\mathrm{Al}$ & 99.8 \\
\hline $\mathrm{Cu}, \mathrm{Mn}, \mathrm{Si}, \mathrm{Zn}$ & $0.03,0.02,0.15,0.06$ \\
\hline Other element (Fe, Mg, Ti, Ga ) & $0.15,0.02,0.02,0.03$ \\
\hline
\end{tabular}

Drawing process must be selected in appropriate manner to reduce the problem arise during drawing, 
because material is very soft. It can be strengthened by cold working, but not by heat treatment. This process produces aluminum shape in the form of foil, plates, round bar or rod, sheets, stripes, and wire. The aim of this work is to findout relationship between drawing force and semi -die angle, bearing length and reduction in area. This work verifies the finite element model, which can be achieved through the comparison of finite element result with previous analytical models which can be found in many literatures.

Tang et al. [4] analysed numerical simulation of damage evolution in multi pass wire drawing process using Garson-Tvergaard-Needleman (GTN) model. Defects produced during 8-pass were analysed by simulation optimization of process parameter and numerical analysis was conducted. Based on the principle of least damage accumulation in the drawing process, the optimum area reduction is chosen and selection of material process was done.

Hassan et al. [5] analysed the drawing process parameters using a 3D finite element model and the effect of these parameters on drawing force. The results showed that the optimum die angle depends on reduction in area. The drawing forces estimated from finite element results was compared with that of analytical results. The drawing velocity has significant effect on drawing force, when the drawing velocity increases the drawing force decreases and the increase of bearing length causes an increase in drawing force, to avoid the increase of drawing force, the reduction in area and friction coefficient should be small with a large die angle. DEFORM-3D was successfully used to simulate the wire drawing process the adopted model showed a desirable agreements with the results of the analytical method with a maximum error of $4 \%$.

Cao et al. [6] analysed comparison of reduction ability between multistage cold drawing and rolling of the stainless steel wire. Test is carried out and higher reduction can be obtained with drawing process and ductile damage can be investigated by numerical simulations. In this study, two phenomenological damage models were calibrated and small die angle was used to reduce the risk of central burst. The shear effect and friction on the wire surface must be controlled due to the high contact length.

Haddi et al. [7] analyzed the temperature and speed effect on drawing stress for improving the wire drawing process. Thermocouple and load cell system are used to measure the temperature rise and drawing stress for different drawing speed. The result obtained show that drawing stress and temperature rise vary during the drawing process. From the experimental results a relationship between temperature rises, friction co-efficient and drawing stress was build up. A modification of the Avitizur's model was presented. This new model provided the process parameters which satisfy the condition of minimum drawing stress for copper material. A comparative study had been done between analytical method and finite element method (FEM). Two materials $\mathrm{Cu}$ and steel had been tested under different friction condition. They observed that optimum die angle slightly decreases with increase of drawing velocity.

Celentano et al. [8] evaluated simulation and experimental validation of multiple step wire drawing process. A tensile stress was carried out to characterise the material hardening evolution for different consecutive wire reduction. Drawing forces was also measured in multiple step wire drawing for different drawing velocity. After that a finite element formulation and problem simulation has been done. During simulation large viscoplastic strain and friction effect was considered. After simulation, result obtained is experimentally validated.

Lee et al. [9] analysed design of multistage wet wire drawing process for improving drawing speed for high carbon $(0.72 \% \mathrm{C})$ steel wire. In this study wire temperature variations observed. After that no of passes executed for 
preventing the rise in wire temperature. A new machine designed to implement the new pass schedule at high speed for improvement of productivity. The no of passes can be increased from 24 to 29 in order to increase the final drawing speed from $1100 \mathrm{~m} / \mathrm{min}-2000 \mathrm{~m} / \mathrm{min}$. Wire temperature calculation model for wet wire drawing process was used and appropriate pass schedule was also considered. Finally the final drawing speed was doubled with respect to current drawing process.

Karbayama et al. [10] analysed influence of die geometry on stress distribution by experimental and FEM simulation on electrolytic copper wire drawing. The experimental results showed that the friction coefficient decreases as the wire drawing speed is increases. The simulation showed a variation in the radial and axial tension. Gawali et al. [11] Investigated the effect of high speed drawing $(25 \mathrm{~m} / \mathrm{sec})$ on mechanical and technological properties of high carbon steel wire. Wire rod $5.50 \mathrm{~mm}$ from steel grade $0.46 \%$ carbon and $0.71 \%$ carbon were drawn to $1.35 \mathrm{~mm}$ in 13 draws and two speeds $8 \mathrm{~m} / \mathrm{sec}$ and $25 \mathrm{~m} / \mathrm{sec}$. After each draw the following properties were determined; tensile strength (Ts), temperature (T), number of twists (Nt), number of bends (Nb). A large drop in the number of has been observed for final wires because of increased draw speed. However, there is also an advantage as the wire surface is much smoother after drawing at high speed than at low speed. The results were practically and statistically estimated.

Dukic and Nozic [12] investigated limiting value of maximal logarithmic strain in multistage cold forming operations. Maximum logarithmic strain was achieved in one operation. Strain value had direct impact on operation which was needed. Stability of multistage process like ironing depends to great extent on redistribution of strain value between single die that was the special case in the mass production.

Kuboki et al. [13] analysed design method of die geometry and pass schedule by void index in multi pass drawing. In multi pass drawing void growth suppressed by the die geometry design. Void index evaluated void fraction in multi pass drawing that based on well known equation to predict the fraction limit in cold working. The influence of the die geometry on void index investigated by using finite element analysis. It clarified that extra low angle is effective whatever reduction in area is adopted. Dies designed as to have the effective suppressing void with minimum die length. A series of experiments were carried out to verify the numerical results.

Raji et al. [14] analysed influence of degree of cold drawing on the mechanical property of low carbon steel. Low carbon steel used for manufacturing nails. Steel wire $0.3 \%$ carbon was cold drawn through a series of drawing dies to reduce the diameter of wire to required diameter of nails. $12 \%$ carbon steel wire cold drawn progressively by $20 \%, 25 \%$, $40 \%, 50 \%$ investigated. Mechanical properties of cold drawn wire studied by tensile test, impact test, and hardness test. Izod test determined the toughness, tensile test done to investigate the yield strength and tensile strength of material as degree of deformation increases. In this paper buckling and brittle nature of some nails in service was established.

Sawamiphakdi et al. [15] investigated the effect of residual stress in drawn wire by the finite element method. Parametric study was conducted to investigate the effect of die geometry and area reduction factor on magnitude and distribution of residual stress through the wire crossection. Two major variables studied die angle and die radius. Parametric studies indicated that die inlet angle had significant effect on the residual stress at the surface of drawn wire.

Wiewiorowska et al. [16] evaluated the experimental and numerical analysis of the trip steel wire drawing process drawn with different partial reduction. In this study numerical analysis of drawing process with use of $2 \mathrm{D}$ programme, for steel wire made from trip steel with $0.29 \%$ had been shown in work. The change in strain value of 
redundant strain determined for particular draws in dependence of used single partial reduction. The change in strain intensity and redundant strain value of partial reduction determined from the theoretical analysis of multistage drawing process.

Masse et al. [17] investigated optimal die semi angle concept in wire drawing examined using automatic optimization techniques. In the investigation of concept of optimal dies semi angle in wire drawing used coupling of evolutionary algorithms with Meta model of damage simulation optimization of damage and wire drawing forces suggested a refined vision of optimal dies semi angle concept. It presented that a die semi angle slightly above the optimum. In this paper meta model base evaluation algorithm that demonstrate their robustness and efficiency to analytical problem and complex forming process used, in order to precise the optimal die angle concept in the wire drawing.

Lee and Tarng [18] evaluated drawing parameters selection for maximizing production rate or minimizing production cost in multistage drawing process. This paper investigated about drawing parameter for maximum production rate or minimum production cost in multistage wire drawing process. A polynomial network constructed to develop relationship between parameter such as speed and wire drawing performance such as applied force, die angle etc. The optimal drawing parameter subjected to an objective function of maximum production rate or minimum production cost with constraint of permissible limit of surface roughness, forces and feasible range of drawing parameters.

Domiaty et al. [19] investigated temperature rise in wire drawing. The work objective was focussed on the practical knowledge area. The result obtained were used by design manufacturing to select the process which satisfied the condition of minimum temperature rise and maximum energy saving for ten different materials. Process parameter dies angle, friction, force, speed reduction ratio calculated for different ten materials. The predicted value of temperature rise was compared with the experimental finding in literature to examine the validity of prediction techniques.

Dolge and Kroff [20] analysed FEM simulation of multistage drawing with drawing force considering the material damage. In this paper FE- ABAQUS / STANDARD 5.7 used to perform automated multistage simulation of wire drawing process. Investigation showed that drawback force had a strong influence on resulting stress state.

Suliga et al. [21] analyzed the high speed wire drawing process of high carbon steel wire under hydrodynamics lubrication conditions. In this paper, analysis of wire drawing process was done in hydrodynamic dies. The drawing process of wire diameter of $5.5 \mathrm{~mm}$ wire rod to final wire of diameter $1.5 \mathrm{~mm}$ conducted in 12 passes. Drawing speed was $5-25 \mathrm{~m} / \mathrm{s}$. The topography of wire surface investigated amount of lubrication on the wire and pressure of lubricant in hydrodynamic dies. The industrial trial of high speed drawing process of high carbon steel showed that multi sodium lubricant improved the lubricating conditions significantly..

Skolyszewski and Packo [22] determined back tension value in fine wire drawing process. They investigated that any known condition based on result of uniaxial tensile test approximate value of critical back tension stress were determined. Production of fine wire of high alloy steel through multi stage drawing would be improved with no back tension. Paper was focused on two problems, first was to develop relation between the critical back tension value and mechanical properties of materials, second one is for industrial investigation of optimization of fine wire multistage slip drawing problem.

Eiji et al. [23] analyzed the metallurgy simulation for the metal drawing process optimization by using two scale finite element methods. Two scale FE analysis procedure was developed based on the crystallography homogenization 
method by considering the hierarchical structure of poly-crystal $\mathrm{Al}$ alloy metal. This FE analysis code predicted the deformation strain, stress evaluations in the wire drawing process in micro scales.

Cho et al. [24] analyzed the effect of reduction ratio, inclusion size, and distribution between inclusions in wire breaks in copper fine wire drawing. The investigation aim was, determining the reduction ratio when size of an inclusion, application of back tension and distance between inclusions was considered. They investigated about effect of back tension on the break of wire. FEM code was used with commercially available deform 2D.

Wang et al. [25] investigated a method for identifying the key quality characteristics in multistage manufacturing process based on partial least square regression (PLSR). To improve the existing method identifying the quality characteristics in multistage manufacturing process, combined two methods, state space model and partial least square regression method. By use of model, a relationship was developed between quality characteristics.

Chen et al. [26] investigated the microstructure of $\mathrm{Cu}$ coated $\mathrm{Al}$ wire. $\mathrm{Cu}$ coated $\mathrm{Al}$ wires exhibit good electrical conductivity, high thermal conductivity, low contact resistance of $\mathrm{Cu}$ and low density, and provide economic advantages over $\mathrm{Al}$. In this work, the hot-dip $\mathrm{Cu}$ coating method of $\mathrm{Al}$ wires investigated for producing $\mathrm{Cu}$ coated $\mathrm{Al}$ wire composites. The interface microstructure between the $\mathrm{Al}$ wire and the $\mathrm{Cu}$ coating layer analyzed by scanning electron microscopy (SEM) and energy-dispersive X-ray spectrometry (EDS).

Roy et al. [27] optimized the design of multistage metal forming processes with micro genetic algorithms. For optimization of process variables in multistage forming process a new method was introduced which was micro genetics algorithm. Design by numerical simulation was trial and error procedure, where objective was to find the cost effective process to manufacturing a defect free product by varying process parameters. This study explained about the micro genetics algorithm in optimization of multistage forming process.

Allen and Phelan [28] analyzed the axisymmetric wire drawing by means of a coupled damage model. By use of this modified damage work model, they analyzed the occurrence of central burst defect in manufacturing and multi pass wire drawing. Die land had negligible effect on the mechanical properties and required drawing load. Periodic variation was effective strain along surface of wire due to central bursting. These variations showed that bamboo defects which is the main reason of central burst. Study showed that central burst propagates from internally due to presence of hydrostatics tensile stress along the centre line of the deformation zone.

Ko et al. [29] evaluated $\mathrm{Cu}$ coating ratio in steel / $\mathrm{Cu}$ clad wire drawing. Steel wire with $\mathrm{Cu}$ wire clad was used for study for optimization of drawing process. Bimetal has good strength, good conductivity and corrosion resistance. This paper investigated about the effect of variable process parameters such as semi die angle, reduction in area and maximum damage value and coating ratio. FEM had been used to simulate the deformation pattern of composite materials. This study examined the effect of semi die angle and reduction in area on coating ratio of steel / $\mathrm{Cu}$ clad wire. From FE analysis, the final coating ratio depends upon initial coating ratio in the multistage clad wire drawing process. Multistage clad wire drawing experiment verified the FE analysis.

Tasevski et al. [30] investigated system dynamics between the two stages of wire drawing machine. Experimented investigation was conducted on the basis of two stages of wire. The wire drawing machine analysis had been done. Analysis concluded that influence of distribution on two wire drawing stages of the machine drawing condition wire drawing through reduction matrices for different drawing speed. They found that dynamic behavior of capstan and roller of 
same drawing stages in homogeneous deformation in wire causes changes in the tensile force.

Celano et al. [31] analysed the effective artificial intelligence technique in optimal design of multi pass cold drawing process. In this study, balance drawing stress was achieved on material along no of passes. This work present average mechanical property of product measured with application of tension test of flat and cylindrical specimen. The influence of no of passes on the change in plastic and strength properties of flat and round product was analysed.

Luksz and Burdek [32] investigated the influence of the deformation mode on the final mechanical properties of products in multi-pass drawing and flat rolling. The mechanical properties of products (tensile strength, yield strength, percentage elongation) were evaluated after the last pass. Strength and plastic properties had changed at the increase of no of passes. This work present average mechanical property of the products measured with application of tension test of flat and cylindrical specimens.

Suliga [33] analyzed the heating of steel wire during high speed multi pass drawing process. The decrease in thickness of the layer can be explained by a shorter time of heat transfer to the wire, which causes additional heat accumulation in the surface layer. Thus the increase in drawing speed causes increase in the temperature in the surface layer of the wire. At high drawing speeds, the temperature of surface layer of wire was increased to the range of temperature at which thermal decomposition of the lubricant was formed and time of appearance of high temperature on the wire surface was very short. The analysis of heating of wire showed that in the multistage drawing process, an increase in drawing speed causes intense heating of a thin surface layer of the wire to a temperature exceeding $11000 \mathrm{c}$. It has been showed that with increasing of drawing speed, the heated surface layered thickness measured at the exit of the wire from the dies is reduced significantly and a drawing speed of $25 \mathrm{~m} / \mathrm{s}$ is equal to about $68 \mu \mathrm{m}$.

\section{CONCLUDING REMARK}

The following conclusions may be achieved from the literature review

- $\quad$ The materials used for wire drawing are stainless steel, high carbon steel, copper etc.

- Experiments have been conducted on various parameters like speed, temperature, friction, stress, force, area of reduction, die angle etc.

- Different methodologies have been used to improve surface finish of wire and optimization of process parameters.

- $\quad$ By optimization of process parameters, a better quality wire can be produced.

- Most of the authors preferred to use GTN model into ABAQUS with VUMAT, FEM analyses, Modified damage work model and GTN model.

- The drawing velocity has significant effect on the drawing forces, if drawing velocity increases the considerable decrease in drawing forces take place due to yield strength and ultimate tensile strength for the material.

\section{SCOPE FOR THE FUTURE WORK}

- $\quad$ Al 1080A will be used for multistage wire drawing, because it is abrasive and hard in behavior which is challenging in multistage wire drawing for small diameter of wire.

- A simulation application software DEFORM 3D Ver 10.2 will be used for process optimization. 
- Hit and Trail method will be used for selecting the input process parameters.

- Reduction area and friction condition at interface with constant die exit angle will be selected with constant velocity in multistage wire drawing.

- Lagrangian increment with conjugate gradient solver with direct method will be selected for simulation of multistage wire drawing process.

- Output responses in post processing will be analyze and effect is investigated for load, effective stress, strain effective, strain rate effective, and damage etc.

- A new process design model will be developed with optimized process parameters and validate.

\section{REFERENCES}

1. R Chandramoulli, "Wire and bar Drawing-Basic Concepts", NPTEL Mechanical engineering forming, Vol.6, pp. 1-8

2. Egon Braun, "Multistage wire drawing machine", Material processing and technology Vol. 493, 1979, pp.1-10.

3. Betzalel Avitzur metal forming process and analysis, Mc Graw-Hill Book Company 1968.

4. K. K. Tang, Z.X. Li, J. Wang, "Numerical simulation of damage evolution in multi-pass wire drawing process and its applications", Material and design, Vol.32.6, 2011, pp.3299-3311.

5. Abdul kareem F. Hassan,Alyaa S. Hashim "The dimensional finite element analysis of wire drawing process" Universal journal of mechanical engineering vol, 2015, pp.71-82.

6. T.-S. Cao, C Vachey, P. Montmitonnet, P.-O Bouchard, "Comparison of reduction ability between multistage cold drawing and rolling of stainless steel wire -Experimental and numerical investigations of damage", Journal of material processing technology, Vol.217, 2015, pp.30-47.

7. A. Haddi, A. Imad, G. Vega, "Analysis of temperature and speed effect on the drawing stress for improving the wire drawing process", Material and design, Vol. 32.8, 2011, pp.4310-4315.

8. Diego J. Clentano, Mauricio A. Palacios, Ennio Raja, Marcela A. Creechaga, Alfredo A. Artigas, Alberto E. Monsalve, "simulation And experimental validation of multiple step wire drawing processes", Finite elements in analysis and design, Vol.45.3, 2009, pp.163-180.

9. Sang-Kon Lee, Seon-Bong Lee, Byung - Min Kim, "Process design of Multi- stage wet wire drawing for improving the drawing speed for $72 \mathrm{wt} \%$ C steel wire”, Journal of materials processing technology, Vol.210.5, 2010, pp.776-783.

10. Lenardo kyo kabayama, simone Pereira Taguani, Gustaro Aristides Santana, "The influence of die geometry on stress distribution by experimental and FEM simulation on electrolytic copper wire drawing", Materials research, Vol.12.3, 2009, pp.281-285.

11. Prakash Gawali, Amitesh paul, G. R. Selokar, "Effect of high speed drawing on properties of high carbon steel wires", Internatinal journal of Modern Engineering Research, Vol.2, Issue.2, pp.209-214, 2012.

12. Himzo Dukic, Mirna Nozic, "Limiting value of maximal logarithmics strain in multistage cold forming operation", Journal for technology of plasticity, Vol.40.1, 2015, pp.104-120.

13. Takashi kuboki, Masaakinabe, yutaka, Neishi, Masayoshi Akiyama, "Design method of die geometry and pass schedule by void index in multistage wire drawing”, Journal of manufacturing science and engineering,Vol.127.1, 2005, pp.173-181. 
14. Nurudeen A. Raji, Oluleke O. Oluwole, "Influence of degree of cold drawing on the mechanical properties of low carbon steel", Material science and applications, Vol.2.11, 2011, pp.15-56.

15. K. Sawamiphakdi, K.P. K. Kropp and G. D. Lahoti, "Investigation of residual stresses in drawn wire by the finite element method", Journal of engineering materials and technology, Vol.112, 1990, pp.231-235.

16. Wiewiorowska, Sylwia and Zbigniew Mikulski, "The Experimental and Numerical Analysis of Trip Steel Wire Drawing Processes Drawn with Different Partial Reductions", International Journal of chemical, molecular, nuclear, materials and metallurgical engineering, Vol. 9.12, 2015, pp.1349-1352.

17. T. Massé, L. Fourment,P. Montmitonnet, C. Bobdilla S. Foissey, "The optimal die semi-angle concept in wire drawing, examined using automatic optimization techniques", International journal of material forming, Vol. 6.3, 2013, pp.377-389.

18. B.Y.Lee and Y. S. Tarng, "Cutting-parameter selection for maximizing production rate or minimizing production cost in multistage turning operations", Journal of materials processing technology, Vol. 105.1, 2000: pp.61-66.

19. El-Domiaty, Aly, and Sadek Z. Kassab, "Temperature rise in wire-drawing”, Journal of materials processing technology, Vol.83.1, 1998, pp.72-83.

20. Eckart Dolge and Andre Kroff, "FEM-Simulation of Multistage Wire Drawing with Backward Force Considering the Material Damage”, Journal for manufacturing science and production, Vol. 2.4, 1999, pp.189-198.

21. M. Suliga, "Analysis of high speed wire drawing process of high carbon steel wire under hydro dynamically lubrication conditions", Archives of metallurgy and materials, Vol.60, 2015, pp.66-70.

22. A.Skolyszewski, M. Packo, "Back tension value in fine wire drawing process", journal of material processing technology, Vol.80, 1998, pp.380-387.

23. Nakamachi Eiji, Youshida, Takashi, Yamaguchi, Toshiko, Morita, Yusuke Kuramae, Hiroyuki, Morimoto, Hideo, "Process metallurgy simulation for metal drawing process optimization by using two-scale finite element method", Internatinal conference of computational method in science and engineering, Vol. 1618, 2014, pp.323-326.

24. Hoo Cho, Hyun ho Jo, Sang Hon Lee, Byung min kin, Young sig kim, "Effect of reduction ratio, inclusions size and distance between inclusion on wire breaks, in cooper fine wire drawing”, Journal of processing technology,Vol.130, 2002, pp.416-420.

25. Ning Wang, Jichao Xi, Jainfeng, “Method of identification key quality characteristics in multistage manufacturing process based on PLSR", Applied mechanics and materials, Vol.217-219, 2012, pp. 2580-2584.

26. Xiao Hua Chen, Xin Tang, Z.Dong Wang, Xi Dong Hui, Moli, Yong Wei Wang, "Manufacturing process and microstructure of copper-coated aluminum wires", International journal of minerals and metallurgy and materials, Vol. 22, 2015, pp. 190-196.

27. S. Roy, S. Ghosh, R. Shivpuri, “ A new approach to optimal design of multistage metal forming processes with micro genetic Algorithms", International Journal of mechanical tool and manufacturing, Vol.37, 1997, pp.29-38.

28. P.J. Mc.Allen, Pat Phelan, "Numerical analysis of axisymmetric wire drawing by means of a coupled damage model", Journal of material processing technology, Vol.183, 2007, pp.210-218.

29. D.C.Ko, S.K.Lee, B.M.Kim, H.H.Jo,H.Jo, “Evaluation of copper coating ratio in steel /copper clad wire drawing”, Journal of material processing technology,Vol.186, 2007, pp.22-26.

30. Goce Tasevski, Kocho Angjushev, Zlatko Petereski,Dejan Shishkovski "Experimental measurement of system dynamics between two stages of wire drawing machine”, Archives of mechanical engineering, Vol.62.1, 2015, pp.61-72.

31. S. Celano, S. Fichera, L. Fratini, F. Micari, "The application of AI techniques in the optimal design of multi-pass cold 
drawing processes", Journal of materials processing technology, Vol, 113.1, 2001, pp.680-685.

32. Janusz Lukasz, Marek Burdek, "The influence of the deformation mode on the final mechanical properties of product in multipass drawing and flat rolling”, Journal of materials processing technology, Vol.125, 2002, pp.725-730.

33. M. Suliga, "Analysis of heating of steel wire during high speed multi pass drawing process", Archives of metallurgy and material, Vol.59, 2014, pp.251-268. 
